\title{
Symptoms of common mental disorder and cognitive associations with seropositivity among a cohort of people coming for testing for HIV/AIDS in Goa, India: a cross-sectional survey
}

Rosie Mayston ${ }^{1 *}$, Vikram Patel $^{2,3}$, Melanie Abas ${ }^{1}$, Priya Korgaonkar ${ }^{3}$, Ramesh Paranjape $^{4}$, Savio Rodrigues ${ }^{5}$ and Martin Prince ${ }^{1}$

\begin{abstract}
Background: The majority of research on HIV/AIDS and mental health has been carried out among clinical populations: the time of onset of comorbid depression and the mechanisms for this are therefore unclear. Although there is evidence to suggest that asymptomatic people living with HIV/AIDS exhibit some cognitive deficits, the prevalence of poor cognitive functioning among people in low income settings at an early, pre-clinical stage has not yet been investigated.

Methods: We used a cross-sectional survey design to test the hypotheses that symptoms of Common Mental Disorder (CMD) and low scores on cognitive tests would be associated with seropositivity among participants coming for testing for HIV/AIDS. Participants were recruited at the time of coming for testing for HIV/AIDS; voluntary informed consent was sought for participation in research interviews and data linkage with HIV test results. Baseline questionnaires including sociodemographic variables and measures of mental health (PHQ-9, GAD-7, panic disorder questions, AUDIT and delayed word list learning and recall and animal naming test of verbal fluency) were administered by trained interviews. HIV status data was extracted from clinical records.

Results: CMD and scoring below the educational norm on the test of verbal fluency were associated with testing positive for HIV/AIDS in bivariate analysis $(\mathrm{OR}=2.26,1.31-3.93 ; \mathrm{OR}=1.77,1.26-2.48$, respectively). After controlling for the effects of confounders, the association between CMD and seropositivity was no longer statistically significant $(A O R=1.56,0.86-2.85)$. After adjusting for the effects of confounders, the association between low scores on the test of verbal fluency and seropositivity was retained ( $A O R=1.77,1.27-2.48$ ).

Conclusions: Our findings provide tentative evidence to suggest that low cognitive test scores (and possibly depressive symptoms) may be associated with HIV status among people who have yet to receive their HIV test results. Impaired cognitive functioning and depression-like symptoms may be the result of the same underlying neurological damage. CMD and cognitive impairment may overlap to a greater extent than previously assumed. If replicated, this may have implications for the way in which we measure and treat CMD and cognitive functioning among people living with HIV/AIDS.
\end{abstract}

\footnotetext{
* Correspondence: rosie.mayston@kcl.ac.uk

${ }^{1}$ Health Service \& Population Research Department, Institute of Psychiatry,

Kings College London, London, UK

Full list of author information is available at the end of the article
} 


\section{Background}

High levels of common mental disorder have been identified among people living with HIV/AIDS in communities around the world [1-5], including in India [6]. There is evidence from low and middle income and high income settings that Common Mental Disorders (CMD) such as depression have an adverse impact upon adherence [7-9], as well as additional negative effects upon HIV-related clinical outcomes such as disease progression and survival, that are independent of the effects of common mental disorder upon adherence [10,11]. Neurocognitive impairment usually thought to be due to HIV-related damage to the frontostriatal region of the brain is generally found to occur among 20-37 percent of people living with HIV/AIDS [12] and is associated with HIV-associated dementia, disease severity [13], mortality [14], adherence to antiretroviral therapy [15] and employment [16]. The precise mechanisms for the high prevalence of comorbid neurocognitive impairment with HIV/AIDS are not well understood but recent studies have found reduced subcortical volumes and metabolite abnormalities among HIV-positive participants on cART [17].

Although diagnosis and life events related to diagnosis and disclosure undoubtedly contribute to the poor mental health of people living with HIV/AIDS $[18,19]$, there is evidence to suggest that the presence of HIV in the brain may also play a role in producing depression-like symptoms [20]. The majority of research on HIV/AIDS and mental health has been carried out among clinical populations: the time of onset of comorbid depression and the mechanisms for this are therefore unclear. Although there is evidence to suggest that asymptomatic people living with HIV/AIDS exhibit some cognitive deficits [21], the prevalence of poor cognitive functioning among people in low income settings at an early, preclinical stage has not yet been investigated.

The few researchers who have measured depression among people coming for testing in low income settings have generally found a high prevalence (45 percent in an Indian sample [6]; 41 percent among pregnant women in South Africa [22]). Depression was not found to be associated with testing positive for HIV/AIDS in either these samples.

The limited data available on HIV-associated cognitive impairment in low income settings generally indicates lower cognitive functioning among seropositive participants as compared to seronegative controls [12]. Prevalence estimates of impairment vary- a multicentre WHO survey found impairment among symptomatic individuals of between 13 and 19 percent [21], whereas recent studies carried out in India, China, Uganda and Botswana comparing HIV-positive with HIV-negative controls reported prevalence of between 31 and 56 percent $[12,23]$.
The aim of the Umeed study was to investigate the relationship between CMD symptoms cognitive functioning and HIV/AIDS among a cohort of people attending a public clinic for HIV-testing. At the time of interview, study participants were not aware of their HIV status. Given the evidence to support a biological pathway between HIV infection and common mental disorder and cognitive impairment, we hypothesised that CMD symptoms and cognitive impairment would predict testing positive for HIV/AIDS among a sample that were not yet aware of the outcome of their test.

\section{Methods \\ Design}

Analysis of cross-sectional data from the "Umeed" cohort is presented here. Participants were recruited at the time of attending for pre-test counselling and testing for HIV/AIDS at Goa Medical College. Structured interviews including questions about demographics, HIVrelated factors, as well as measures of CMD symptoms and alcohol and substance misuse were carried out in the clinic setting at the time of attendance for pre-test counselling and testing. Participants were then followed up via routine records in order to obtain HIV status and attendance of post-test counselling data.

In order to test the hypothesis that CMD symptoms and/or cognitive impairment would predict seropositivity among those without knowledge of their HIV status, study participants who reported having previously been tested for HIV/AIDS and who had received a seropositive result were excluded from analyses $(n=57)$ presented in Tables 1, 2, 3, 4 and 5 .

\section{Setting}

Goa, the smallest Indian state by area, is situated on the west coast between Maharashtra and Karnataka and has a population of 1.34 millions (Government of Goa, 2010). For HIV/AIDS surveillance, Goa is divided into two districts: the north is described as one of India's high prevalence districts, with more than one percent prevalence among women at antenatal care. The south is medium prevalence, with more than five percent prevalence found among those attending STI clinics (high risk group) (UNAIDS, 2008).

\section{Recruitment and measures}

Participants were recruited at the time of attending the largest public Integrated Counselling \& Testing Centre (ICTC) for pre-test counselling and testing. In 2008, 20.8 percent of attendees were "walk-in", self-referrals, whilst the majority of people tested attended upon the recommendation of a Doctor (Goa State AIDS Control Society, 2012). Doctors refer participants for testing for a variety of reasons, including: unexplained or suspected 
Table 1 Characteristics of the sample

Total
Male
Female
Age
$18-25$
$26-30$
$31-34$
$35-40$
$41-45$
$46-50$
$51+$
Language
Hindi
Konkani
English
Religion
Hindu
Christian
Muslim
Other
State of

State of origin

Goa

Other than Goa

Marital status

Married/co-habiting

Widowed

Separated/divorced

Never married

Education

None

Primary school

Secondary school

Further education

CMD symptoms

Symptoms of major depression

Symptoms of generalised anxiety

Symptoms of panic

Symptoms of major depression + scored more than 5 on GAD-7

Symptoms of generalised anxiety + scored more than 5 on PHQ-9

Symptoms of panic + scored more than 5 on PHQ-9

Abstinent/occasional alcohol use

Harmful alcohol use

\begin{tabular}{lr}
\multicolumn{3}{l}{ Prevalence $\mathbf{n}(\%)$} \\
1874 \\
880 & $(47.0)$ \\
994 & $(53.0)$
\end{tabular}

441

(23.5)

190
Table 1 Characteristics of the sample (Continued)

Cognitive functioning

Delayed recall- Scored below

427

educational

norm

Verbal fluency- Scored below

480

educational norm

Experienced domestic violence in the last $12 \mathrm{~m}$

Yes

116

Perpetrated domestic violence in the last $12 \mathrm{~m}$

Yes

81

Frequency of social outings, ie. visiting a friend/relative

Often (at least 1/week)

94

Sometimes (at least 1/month)

Rarely (less than once $1 /$ month)

Never

Frequency of having friends/relatives coming to visit

Often (at least 1/week)

Sometimes (at least 1/month)

Rarely (less than once 1/month)

Never

Ever experienced hunger due to lack of money

Yes

Accompanied to the ICTC

No

Plan to disclose HIV/AIDS test results

Yes

No

Don't know

Knowledge of HIV prevention

Thorough

Partial/poor

Knowledge of HIV transmission

Thorough

Partial

Poor

Internalised stigma v. people living with HIV/AIDS

None

675

Moderate

Strong

Anticipated stigma if tested positive for HIV/AIDS

None

602 
Table 1 Characteristics of the sample (Continued)

\begin{tabular}{|c|c|c|}
\hline Moderate & 511 & $(27.3)$ \\
\hline Strong & 761 & (40.6) \\
\hline \multicolumn{3}{|c|}{ Ever injected a non-prescription drug } \\
\hline Yes & 2 & $(0.1)$ \\
\hline \multicolumn{3}{|l|}{ Ever had sex } \\
\hline No & 293 & 15.20 \\
\hline \multicolumn{3}{|c|}{$\begin{array}{l}\text { Male who had sex with a man during } \\
\text { the last year }\end{array}$} \\
\hline Yes & 14 & 0.75 \\
\hline \multicolumn{3}{|c|}{$\begin{array}{l}\text { Ever had sex with someone other than } \\
\text { your regular partner in last } 12 \mathrm{~m}\end{array}$} \\
\hline Yes & 225 & $(12.0)$ \\
\hline \multicolumn{3}{|c|}{$\begin{array}{l}\text { Ever received cash, gifts or favours in } \\
\text { exchange for sex }\end{array}$} \\
\hline Yes & 33 & (1.8) \\
\hline \multicolumn{3}{|c|}{$\begin{array}{l}\text { Ever had sex with someone who was } \\
\text { a commercial sex-worker }\end{array}$} \\
\hline Yes & 90 & (4.8) \\
\hline \multicolumn{3}{|c|}{$\begin{array}{l}\text { Has experienced pain/burning with } \\
\text { urination }\end{array}$} \\
\hline Yes & 364 & (19.4) \\
\hline \multicolumn{3}{|l|}{ Genital sores } \\
\hline Yes & 119 & (6.4) \\
\hline \multicolumn{3}{|l|}{ Genital warts } \\
\hline Yes & 61 & (3.3) \\
\hline \multicolumn{3}{|c|}{ Genital discharge } \\
\hline Yes & 327 & (17.5) \\
\hline \multicolumn{3}{|c|}{ Believes likely to test positive for HIV/AIDS } \\
\hline Yes & 35 & (1.9) \\
\hline Don't know & 478 & $(25.5)$ \\
\hline \multicolumn{3}{|c|}{$\begin{array}{l}\text { Have a child or partner who is HIV- } \\
\text { positive }\end{array}$} \\
\hline Don't know & 106 & $(5.7)$ \\
\hline Yes & 106 & $(5.7)$ \\
\hline \multicolumn{3}{|l|}{ HIV status } \\
\hline Positive & 164 & (8.8) \\
\hline
\end{tabular}

HIV-related symptoms, pre-operative tests. Self-referrals include those who believe themselves to be at high-risk as well as those undergoing pre-marital tests or testing before going to work abroad. Potential participants were informed about the study by trained research assistants; consent for participation and data linkage with test results was sought. The study was approved by local and international research ethics committees (Sangath and KCL).

Questionnaires, administered by research assistants using palmtop computers were carried out at the time of participants coming for testing. In order to maximise privacy and quietness, interviews were carried out in purpose-built temporary cabins situated in the clinic reception area. People attending the ICTC for pre-test counselling and testing for HIV/AIDS were eligible to participate if they met the following inclusion criteria: demonstration of capacity- understanding the aims of the study and demands of participation and able to give informed consent; fluent in one of three local languages (Konkani, Hindi \& English); aged more than eighteen years of age. Questions relating to demographics, HIVrelated behaviours, beliefs and knowledge (transmission and prevention knowledge, disclosure plans, sexual behaviour, knowledge and symptoms of sexually transmitted infections) and measures of mental health were included in baseline interviews.

In order to access free-of-charge antiretroviral treatment services, it is necessary to present a test certificate from a state-run testing centre. Therefore, testing in the private sector, followed by re-testing at a public testing centre is relatively common. Participants were therefore asked if they had previously undertaken a HIV-test; those who had received test results were asked to disclose the result to interviewers.

\section{CMD and alcohol use}

A modified version of the Patient Health Questionnaire, the brief PHQ-9, in combination with the 7-item Generalised Anxiety Disorder scale (GAD-7), plus the panic disorder module [24] were included in the baseline questionnaire to measure symptoms of depression, anxiety and panic. In a study comparing the sensitivity and specificity of five screeners for CMD in primary care which carried out in Goa, the PHQ was one of five instruments to achieve an AUC from ROC analysis of at least 0.80 (PHQ AUC = 0.84) [25]. In Umeed, as recommended by Spitzer et al. [24], a cut-off of 10 was used as an indicator for symptoms of major depression. A cut-off of 10 was used to indicate symptoms of severe generalised anxiety [26]. Participants reporting "yes" to each of the first four questions relating to anxiety attacks were indicated as panic disorder cases in the Umeed study. At the time of conducting the study, there were no measures of anxiety symptoms that had been validated in a local HIV-affected population. Therefore, we decided to use brief measures that showed good validity in primary care populations elsewhere. Given the evidence to support distinctive diagnostic categories of depression and anxiety [27-29], participants identified as having symptoms of major depression and/or generalised anxiety disorder and/or panic disorder were categorised as having common mental disorder during analysis. "CMD symptoms" does not refer to a clinical diagnosis but to the result of the screening procedure used in this epidemiological study. 
Table 2 Bivariate associations of with testing positive for HIV/AIDS

\begin{tabular}{|c|c|c|c|c|}
\hline \multirow[b]{2}{*}{ Total } & \multicolumn{2}{|c|}{ HIV-positive n (\%) } & \multirow[t]{2}{*}{ OR $(95 \% \mathrm{Cl})$} & \multirow[t]{2}{*}{$\mathbf{p}$} \\
\hline & 164 & $(8.75)$ & & \\
\hline \multicolumn{5}{|l|}{ Demographics } \\
\hline Male & 78 & $(8.86)$ & 1.00 & 0.97 \\
\hline Female & 86 & $(8.65)$ & $0.97(0.71-1.34)$ & \\
\hline \multicolumn{5}{|l|}{ Age } \\
\hline $18-25$ & 17 & $(3.85)$ & 1.09 (1.00-1.18) & 0.04 \\
\hline $26-30$ & 35 & $(9.80)$ & & \\
\hline $31-34$ & 32 & $(10.96)$ & & \\
\hline $35-40$ & 33 & $(11.70)$ & & \\
\hline $41-45$ & 18 & $(11.11)$ & & \\
\hline $46-50$ & 17 & (11.33) & & \\
\hline $51+$ & 12 & $(6.32)$ & & \\
\hline \multicolumn{5}{|l|}{ Language } \\
\hline Hindi & 72 & $(11.46)$ & 1.00 & \\
\hline Konkani & 91 & $(7.72)$ & $0.65(0.47-0.90)$ & 0.01 \\
\hline English & 1 & $(1.47)$ & $0.12(.0 .02-0.85)$ & 0.01 \\
\hline \multicolumn{5}{|l|}{ State of origin } \\
\hline Goa & 69 & $(6.55)$ & 1.00 & $<0.01$ \\
\hline Other than Goa & 95 & $(11.57)$ & $1.87(1.35-2.58)$ & \\
\hline \multicolumn{5}{|l|}{ Marital status } \\
\hline Married/co-habiting & 119 & $(9.05)$ & 1.00 & \\
\hline Widowed & 23 & $(18.11)$ & $2.22(1.36-3.63)$ & $<0.01$ \\
\hline Separated/divorced & 3 & (23.08) & $3.01(0.82-11.13)$ & 0.08 \\
\hline Never married & 19 & $(4.53)$ & $0.48(0.29-0.79)$ & $<0.01$ \\
\hline \multicolumn{5}{|l|}{ Education } \\
\hline None & 46 & (13.73) & $0.70(0.58-0.84)$ & $<0.01$ \\
\hline Primary school & 44 & $(9.34)$ & & \\
\hline Secondary school & 66 & $(7.21)$ & & \\
\hline Further education & 8 & $(5.23)$ & & \\
\hline \multicolumn{5}{|l|}{ Mental Health and Social Support } \\
\hline No/mild CMD symptoms & 147 & $(8.29)$ & 1.00 & $<0.01$ \\
\hline Moderate/severe CMD symptoms & 17 & $(17.00)$ & $2.27(1.31-3.93)$ & \\
\hline Abstinent/occasional alcohol use & 137 & $(8.38)$ & 1.00 & 0.14 \\
\hline Harmful alcohol use & 27 & $(11.25)$ & $1.39(0.89-2.14)$ & \\
\hline Cognitive functioning & & & $2.47(1.40-4.34)$ & \\
\hline Delayed recall- Scored above educational norm & 117 & $(8.09)$ & 1.00 & \\
\hline Delayed recall- Scored below educational norm & 47 & $(11.01)$ & $1.41(0.98-2.01)$ & 0.06 \\
\hline Verbal fluency-Scored above educational norm & 104 & $(7.46)$ & 1.00 & \\
\hline Verbal fluency- Scored below educational norm & 60 & $(12.50)$ & $1.77(1.26-2.48)$ & $<0.01$ \\
\hline \multicolumn{5}{|c|}{ Frequency of social outings, ie. visiting a friend/relative } \\
\hline Often (at least 1/week) & 3 & $(3.19)$ & $1.53(1.25-1.88)$ & $<0.01$ \\
\hline Sometimes (at least 1/month) & 14 & $(8.92)$ & & \\
\hline Rarely (less than once 1/month) & 56 & $(6.07)$ & & \\
\hline Never & 91 & $(12.98)$ & & \\
\hline
\end{tabular}


Table 2 Bivariate associations of with testing positive for HIV/AIDS (Continued)

\begin{tabular}{|c|c|c|c|c|}
\hline \multicolumn{5}{|c|}{ Frequency of having friends/relatives coming to visit } \\
\hline Often (at least 1/week) & 8 & $(7.14)$ & $1.38(1.14-1.66)$ & $<0.01$ \\
\hline Sometimes (at least 1/month) & 34 & $(7.23)$ & & \\
\hline Rarely (less than once 1/month) & 56 & $(6.87)$ & & \\
\hline Never & 66 & $(13.84)$ & & \\
\hline \multicolumn{5}{|c|}{ Ever experienced hunger due to lack of money } \\
\hline No & 112 & $(7.33)$ & 1.00 & $<0.01$ \\
\hline Yes & 52 & $(14.99)$ & $2.23(1.56-3.17)$ & \\
\hline \multicolumn{5}{|c|}{ Plan to disclose HIV/AIDS test results } \\
\hline Yes & 116 & $(7.79)$ & 1.00 & \\
\hline No & 44 & $(12.94)$ & $1.76(1.22-2.55)$ & $<0.01$ \\
\hline Don't know & 4 & $(8.89)$ & $1.15(0.41-3.28)$ & 0.79 \\
\hline \multicolumn{5}{|l|}{ Ever had sex } \\
\hline No & 12 & $(4.10)$ & 1.00 & $<0.01$ \\
\hline Yes & 152 & $(9.61)$ & $2.49(1.36-4.55)$ & $<0.01$ \\
\hline \multicolumn{5}{|c|}{$\begin{array}{l}\text { Ever had sex with someone other than your regular } \\
\text { partner in last } 12 \mathrm{~m}\end{array}$} \\
\hline No & 136 & $(8.25)$ & 1.00 & 0.04 \\
\hline Yes & 28 & $(12.44)$ & $1.58(1.02-2.44)$ & \\
\hline \multicolumn{5}{|c|}{ Ever had sex in exchange for money, favours or gifts } \\
\hline No & 157 & $(8.53)$ & 1.00 & 0.01 \\
\hline Yes & 7 & $(21.21)$ & $2.89(1.23-6.77)$ & \\
\hline \multicolumn{5}{|l|}{ Ever had genital warts } \\
\hline No & 153 & $(8.44)$ & 1.00 & 0.01 \\
\hline Yes & 11 & $(18.03)$ & $2.39(1.22-4.69)$ & \\
\hline \multicolumn{5}{|c|}{ Believes likely to test positive for HIV/AIDS } \\
\hline No & 72 & $(5.29)$ & 1.00 & $<0.01$ \\
\hline Don't know & 78 & $(16.32)$ & $3.49(2.47-4.93)$ & \\
\hline Yes & 14 & $(40.00)$ & $11.94(5.72-24.91)$ & \\
\hline \multicolumn{5}{|c|}{ Have a child or partner who is HIV-positive } \\
\hline No & 103 & $(6.20)$ & 1.00 & \\
\hline Don't know & 18 & $(16.82)$ & $3.06(1.77-5.29)$ & $<0.01$ \\
\hline Yes & 43 & $(40.57)$ & $10.32(6.54-16.30)$ & $<0.01$ \\
\hline
\end{tabular}

Table 3 Multivariate models adjusting for confounders of association between CMD symptoms and testing seropositive

\begin{tabular}{llll}
\hline Model & Description & Adjusted OR (95\% confidence interval) & P-value \\
\hline 1 & CMD symptoms & $2.27(1.31-3.92)$ & $<0.01$ \\
2 & Model 1 + education & $2.04(1.18-3.56)$ & 0.01 \\
3 & Model 2 + experience of hunger due to lack of money & $1.84(1.05-3.22)$ & 0.03 \\
4 & $1.73(0.99-3.05)$ & 0.06 \\
5 & Model 3 + disclosure plans & $1.65(0.93-2.92)$ & 0.09 \\
6 & Model 4 + genital warts & $1.50(0.83-2.73)$ & 0.18 \\
7 & Model 5 + perceived likelihood of testing positive & $1.56(0.86-2.85)$ & 0.14 \\
\hline
\end{tabular}


Table 4 Multivariate models adjusting for confounders of association between low cognitive functioning score (test 1) and testing seropositive

\begin{tabular}{llll}
\hline Model & Description & Adjusted OR (95\% confidence interval) & P-value \\
\hline 1 & Cognitive functioning: test 1 & $1.41(0.98-2.01)$ & 0.06 \\
2 & Model 1 + age & $1.37(0.96-1.97)$ & 0.08 \\
3 & Model 2 + education & $1.33(0.93-1.90)$ & 0.12 \\
4 & Model 3 + experience of hunger due to lack of money & $1.26(0.88-1.82)$ & 0.21 \\
5 & Model 4 + perceived likelihood of testing positive & $1.17(0.80-1.70)$ & 0.42 \\
6 & Model 5 + cognitive functioning test: verbal fluency & $1.02(0.68-1.51)$ & 0.94 \\
\hline
\end{tabular}

The AUDIT is a 10 item questionnaire designed to measure medium (cut-off of eight) and high levels (cutoff of 16) of alcohol problems (WHO 2001). The instrument has been widely used in India ie. [30,31] and in studies conducted in Goa [32,33]. A recent validity study conducted in Goa demonstrated good sensitivity and specificity for the AUDIT, with an area under the curve of more than 0.80 [34]. For analysis, participants were categorised as hazardous drinkers if they scored above eight.

\section{Cognitive functioning}

Two measures of cognitive functioning were included in the Umeed questionnaire: word list learning (assessing memory) and animal naming (measuring verbal fluency, an aspect of executive functioning, known to be a common deficit in people living with HIV/AIDS- [35]). The terms "low cognitive functioning" and "cognitive deficits" apply to the two domains tested only. Due to the broader aims of Umeed (investigating impact of psychological factors upon access to care) and the practicalities of measuring cognition in a busy clinic setting, we used brief, simple screeners to measure domains that may be impacted by HIV and that were most likely to be implicated in determining access to services.

For the word list learning test, interviewers read out a ten word list (adapted for use in India- [36]) three times. Participants were then asked to recite the list of words after each reading and finally requested to recall words after another section of the questionnaire had been completed. The final total recalled was recorded. For the animal naming test, participants were asked to tell the interviewer as many different types of animals as they could recall during one minute.

These tests originate from the Consortium to Establish a Registry of Alzheimer's Disease (CERAD) test battery and have been validated among an older population in Goa as part of the validation of a cross-cultural diagnostic instrument for dementia [37]. Normative data was available, in the form of education-specific norms derived from the 10/66 study data for the youngest of the older age-group (60-64 years). Education-specific cutpoints for possible cognitive impairment at 1.5 standard deviations below the norms were used in the Umeed study as indicators of low cognitive function.

\section{Outcome measures}

Outcome data was collected from routine clinical records maintained by ICTC staff by an Umeed team member who was not involved in baseline data collection. HIV status and date of attendance of post-test counselling (if attended) was extracted from ICTC records. Study participants records were identified using the unique identifier assigned to participants by counsellors at pre-test counselling.

Table 5 Multivariate models adjusting for confounders of association between low cognitive functioning score : verbal fluency and testing seropositive

\begin{tabular}{llll}
\hline Model & Description & Adjusted OR (95\% confidence interval) & P-value \\
\hline 1 & Cognitive functioning: verbal fluency & $1.77(1.27-2.48)$ & $<0.01$ \\
2 & Model 1 + age & $1.76(1.26-2.47)$ & $<0.01$ \\
3 & Model 2 + education & $1.73(1.23-2.42)$ & $<0.02$ \\
4 & Model 3 + language & $1.65(1.18-2.33)$ & $<0.01$ \\
5 & Model 4 + marital status & $1.71(1.21-2.40)$ & $<0.01$ \\
6 & Model 5 + CMD symptoms & $1.74(1.24-2.46)$ & $<0.01$ \\
7 & Model 6 + has child/partner who is living with HIV/AIDS & $1.63(1.13-2.34)$ & 0.01 \\
8 & Model 7 + perceived likelihood of testing positive & $1.61(1.12-2.33)$ & 0.01 \\
\hline
\end{tabular}




\section{Analysis}

Bivariate analysis was carried out. chi-squared tests were used to test differences between distribution of HIV status outcome between categories of a) hypothesised exposures of interest (common mental disorder, cognitive functioning) and b) potential demographic, HIV-related and psychosocial confounders. Mantel Haenszel odds ratios comparing odds of testing positive for HIV among exposure categories found to be associated with seropositivity in chi-squared analyses are presented in Table 1 with 95 percent confidence intervals.

Where there was evidence from bivariate analysis of an association between exposures of interest and testing positive for HIV/AIDS, multivariate analysis was carried out to further test the hypotheses that CMD symptoms and cognitive impairment would predict seropositivity. Exposures of interest were entered singly into logistic regression models. Potential confounders were then entered one-by-one. Criteria for inclusion in final models were: a) variables considered a priori confounders (for example, association of age with cognitive functioning); or b) variables selected using a "change in estimate" method ie. those that resulted in a significant change in the effect of exposure of interest upon outcome (more than 10 percent change in odds ratio).

\section{Results}

\section{Characteristics of the sample}

As described in Table 1, 8.8 percent of the sample tested seropositive. The majority of the sample were female (53.0 percent); the mean age of participants was 35 years. Almost three quarters were Hindu (73.0 percent) and the majority were born in Goa (56.1 percent). Most were married (70.2 percent); 25.1 percent had attended up to primary school whilst 17.9 percent had received no education at all. 18.5 percent reported ever having experienced hunger due to lack of money.

The prevalence of CMD symptoms among this sample of people of people coming for testing for HIV/AIDS was 5.3 percent. 12.8 percent of participants reported hazardous alcohol use (26.4 percent among men- not presented). Around a quarter of the sample scored below the educational norm on two cognitive tests of delayed recall (22.8 percent) and verbal fluency (25.6 percent).

Analysis of associations with testing positive for HIV/AIDS As described in Table 2, in bivariate analysis, CMD symptoms and scoring below the educational norm on verbal fluency test were associated with testing positive $(\mathrm{OR}=2.27,1.31-3.93 ; \mathrm{OR}=1.77,1.26-2.48$, respectively). There was a trend towards an association between scoring below educational norm on the test of delayed recall and seropositivity $(\mathrm{OR}=1.41,0.98-2.01)$. Hazardous alcohol use was not associated with seropositivity.
All variables found to be associated with testing positive are presented in Table 2. Sociodemographic variables associated with testing positive included: age $(\mathrm{OR}=1.09$, 1.00-1.18), language (those speaking Konkani or English were less likely to test positive than those speaking Hindi: $\mathrm{OR}=0.65,0.47-0.90 ; \mathrm{OR}=0.12,0.02-0.85$, respectively), being born outside of Goa ( $\mathrm{OR}=1.87,1.35-2.58)$, being widowed ( $\mathrm{OR}=2.22,1.36-3.63)$, having experienced hunger due to lack of money $(\mathrm{OR}=2.23,1.56-3.63)$. Visiting relatives or friends (or receiving visits) less than once a week was associated with seropositivity $(\mathrm{OR}=1.53,1.25-$ $1.88, \mathrm{OR}=1.38,1.14-1.66$, respectively). Education was associated with a reduced likelihood of testing positive (OR = 0.70, 0.58-0.84).

A number of HIV-related variables were also associated with seropositivity, including: planning not to disclose test results $(\mathrm{OR}=1.76,1.22-2.55)$, having sex with someone other than a regular partner $(\mathrm{OR}=1.58,1.02$ 2.44), having sex in exchange for cash, gifts or favours $(\mathrm{OR}=2.89,1.23-6.77)$, believing it is likely that the test result will be positive $(\mathrm{OR}=11.94,5.72-24.91)$, having a child/partner who is living with HIV/AIDS (OR $=10.32$, 6.54-16.30).

Variables tested but not found to be associated with HIV status (results not presented in table) included: internalised $(\mathrm{p}=0.16)$ and anticipated stigma $(\mathrm{p}=0.40)$, knowledge of HIV prevention (0.38) and transmission $(\mathrm{p}=0.18)$.

Table 3 shows that, after controlling for the effects of confounders (education, experience of hunger due to lack of money, disclosure plans, genital warts, perceived likelihood of testing positive and verbal fluency), the association between CMD symptoms and seropositivity is no longer statistically significant $(\mathrm{AOR}=1.56,0 . .86$ 2.85). As presented in Table 4, the trend towards an association between delayed recall and testing positive is eliminated by the addition of confounding variables (age, education, experience of hunger due to lack of money, perceived likelihood of testing positive, verbal fluency) to the model $(\mathrm{AOR}=1.02,0.68-1.51)$.

However, as can be seen in Table 5, although the addition of potential confounders of the association between verbal fluency and seropositivity (age, education, language, marital status, CMD symptoms, having a child/partner who is seropositive, perceived likelihood of testing positive) reduced the effect size, in the final model, verbal fluency remains significantly associated with testing positive for HIV/AIDS (AOR = 1.77, 1.27-2.48).

\section{Discussion}

The Umeed cohort is the largest study to describe the mental health of people coming for testing for HIV/ AIDS in a low income setting. The inclusion of seropositive and seronegative attendees of HIV testing provided 
us with a unique opportunity to test hypotheses about mental health and HIV status in the absence of the impact of diagnosis and consequent experiences of living with HIV/AIDS upon participant's mental health. We hypothesised that CMD symptoms and cognitive impairment would be associated with testing positive. Our findings were inconclusive. Although CMD symptoms was strongly associated with testing positive in bivariate analyses, after adjustment for confounders, the effect size of this association was reduced and no longer statistically significant. We found some evidence to support the hypothesised association between low cognitive functioning and seropositivity. Although there was only a bivariate trend towards an association between delayed recall and seropositivity, scoring below education-adjusted norms on the test of verbal fluency (animal naming) was associated with testing positive for HIV/AIDS (AOR $=1.77$, 1.27-2.48).

Almost all of the large body of research about HIV/ AIDS and CMD in low and middle income settings has been carried out among single groups, with a HIVpositive diagnosis, without comparison with seronegative controls (for example, [5,38,39]). A few studies have compared prevalence of depression between seropositive and seronegative groups (ie. $[4,40]$ ). In one of the few studies similar in design to Umeed (a sample of testseekers in Pune where 45.5 percent subsequently received a positive diagnosis), univariate analyses revealed no evidence of an association between common mental disorder and seropositivity [6]. In the Umeed sample, bivariate analysis revealed a strong association between $\mathrm{CMD}$ and testing HIV-positive ( $\mathrm{OR}=2.27,1.31-3.92)$. However, after the gradual introduction of covariates into the model, the effect size was reduced and no longer statistically significant $(\mathrm{AOR}=1.56,0.86-2.85)$.

Although the multivariate analysis presented in Table 3 demonstrates that the association between CMD symptoms and seropositivity was partially confounded by sociodemographic and HIV-related covariates, we should be cautious before interpreting these findings as a demonstration that there was no true association between CMD symptoms and seropositivity. As indicated by the relatively wide confidence intervals presented in Table 3 , the low prevalence of both CMD and seropositivity among Umeed participants (and particularly in the subsample used for this analysis) resulted in reduced power to detect an association, therefore we cannot rule out the existence of a true association between CMD and seropositivity.

As described, the prevalence of CMD symptoms identified among the Umeed sample was much lower than that reported among the two other samples of people coming for testing in low and middle income settings described in the literature. The relatively low prevalence of HIV/AIDS measured in Umeed as compared to these other samples (45.5\% in India; $40.9 \%$ among pregnant women in South Africa) may help to explain the difference in prevalence of CMD symptoms. The Umeed sample is heterogeneous and includes participants at high and low-risk of testing positive. Therefore, it is plausible that the overall prevalence in the Umeed sample may be more similar to that found in the local community [41], rather than that identified in primary care [42]. Without further research among people coming for testing in similar settings, it is difficult to contextualise our findings further. Of course, the possibility that our mode of measurement of CMD symptoms may have contributed to the low reported prevalence of CMD symptoms cannot be ruled out. Although the PHQ-9 is commonly used in Western settings, the lack of validation of cutpoints for use among HIV-affected populations in low income settings may have had an impact upon the low prevalence of common mental disorder identified in the Umeed cohort. As described, all interviews were carried out in temporary, private cabins. All participants were given detailed information about CMD symptoms and the aims and objectives of the study; the PHQ has been found to be valid among a Goan sample of people attending primary care. However, the possibility remains that using the PHQ-9 immediately prior to testing in the busy clinic setting may have inhibited participants willingness to disclose potentially sensitive information about symptoms of anxiety and depression. Our analysis demonstrated a high degree of co-morbidity of symptoms of anxiety and depression within our sample (of those scoring $>10$ on the GAD- 7,75 percent scored $>10$ on the PHQ-9; of those scoring $>10$ on the PHQ-9, 20 percent scored $>10$ on the GAD-7 and 47.4 percent scored between 5 and 10 on the GAD-7), thus supporting the dichotomous "symptoms of CMD" variable used in our analysis.

Given that HIV/AIDS is associated with morbidity, stigma and discrimination $[43,44]$, poverty [45] and mortality $[46,47]$, it is reasonable to expect that living with the disease contributes greatly to the prevalence of CMD among people with HIV/AIDS. However, there is evidence from neurological research to suggest that the inflammatory response that contributes to the neuronal loss that causes HIV-associated cognitive impairment may also trigger cytokine-induced depression [20]. Recent research suggests that even in the absence of other symptoms of depression and cognitive impairment, HIVrelated damage to white matter may be associated with symptoms of apathy ("reduced self-initiated cognitive, emotional and behavioural activity") [48]. In addition to social and environmental risk factors associated with their disease status, people living with HIV/AIDS (and other chronic conditions) may have a biological vulnerability to 
the development of depressive symptoms [46]. Although evidence suggesting that CMD may be associated with risky behaviour $[47,49]$ means that a reverse relationship (pre-existing depression promoting sexual risk-taking and acquisition of HIV) cannot be ruled out, presence of genital warts and perception of HIV-risk were the only sexual risk-related variables, that confounded the association between CMD symptoms and seropositivity- therefore this pathway seems unlikely.

The Umeed finding that low scores on the test of verbal fluency were associated with seropositivity corresponds with the results of a recent meta-analysis that revealed a statistically significant deficit in mean scores on tests of verbal fluency among people living with HIV/ AIDS, as compared to HIV-negative controls ( -0.31 , -0.44 to -0.18 ) [50]. In the only study to compare verbal fluency between seropositive individuals and seronegative controls in India, although HIV-positive individuals differed in other language-related domains (phonemic fluency, verbal working memory and verbal learning and memory); differences in animal naming fluency were not statistically significant [51]. Similarly, statistically significant deficits in verbal learning and memory were identified between seropositive individuals and seronegative controls in a previous south Indian study [52].

Neurological evidence supports the presence of cognitive deficits early in the course of the disease [12]. Both cognitive domains measured in Umeed (category fluency and verbal learning and memory) are consistent with diffuse or frontostriatal pathology, both of which may be characteristic of the effects of HIV-1 on the brain [50]. There is now a growing body of evidence on the cognitive profile of people living with HIV/AIDS in low income settings, including India [52]. Whereas small studies with detailed neuropsychological assessments tend to have stringent exclusion criteria which may limit the generalisability of findings, in Umeed, exclusion criteria were limited, meaning that our sample was likely to be more representative of the base population. The aim of Umeed was to measure cognitive functioning in the selected domains most likely to have an impact upon linkage to care and adherence and to examine whether these were associated with testing positive. The animal naming test of category fluency and the word list learning test of verbal learning and memory were selected as appropriate measures that would be relatively quick and simple for trained research assistants to administer among a large cohort of participants in a busy clinic setting.

The Umeed study design had several other methodological strengths. Unlike other studies that have investigated mental health and HIV/AIDS in a low income setting, the Umeed study was carried out among a large sample that included both seropositive and seronegative individuals recruited prior to diagnosis. Thus we were able to test hypotheses that CMD symptoms, cognitive functioning would be associated with seropositivity independently of the effects of diagnosis. Blind recruitment of seropositive and seronegative participants from the same clinic helped to ensure comparability of the two groups and reduced risk of selection bias. There was evidence from previous research to support the validity of measures of CMD and cognitive functioning among Goan populations.

However, there were also limitations. Due to ethical considerations, those who were potentially most unwell: (ie. unable to participate in 30 minute interview without experiencing undue distress or discomfort or lacking capacity to understand aims, participation demands and give informed, voluntary consent) were excluded from our sample $(n=102)$. Therefore, estimates for CMD symptoms, low cognitive functioning and seropositivity are likely to be lower than the true prevalence among people coming for testing for HIV/AIDS in Goa Medical College. Subsequently, this may have contributed to smaller effect sizes for associations between mental health exposures and HIV status.

It is possible that social desirability bias may have had an impact upon our measures of risk-taking behaviours. Reported risk-taking behaviours were fairly low relative to prevalence of HIV: $0.1 \%$ reported injecting drugs, $0.8 \%$ of men reported having had sex with other men, $1.9 \%$ reported having received money or gifts in exchange for sex; $5 \%$ reported having sex with a sex worker and $12.6 \%$ reported having sex with someone other than a regular partner in the last year. This may have limited our ability to control for the confounding effects of risk-taking behaviours upon observed associations between common mental disorder/low cognitive functioning and HIV status.

There were other limitations to our approach to cognitive testing. The cognitive screening instruments used in Umeed were chosen because they measured the domains most likely to have an impact upon access to care. The education-adjusted norms for cognitive functioning have not been validated among the younger Goan population or in the context of HIV/AIDS. We were unable to discriminate between sub-cortical deficits commonly caused by HIV and cognitive deficits with other causes (educational deprivation, mental sub-normality, language issues etc.), Unmeasured confounding is a possibility. Reverse causality cannot be ruled out. Low cognitive test scores may have been caused by a factor other than HIV that was associated with HIV-risk and acquisition. There is evidence to support a link between heavy alcohol use and poor cognitive functioning [53], as well as an association between alcohol-related impairment and reduced perception of sexual-risk [54]. However, given that we found little evidence of any association between alcohol 
use and HIV status, it seems unlikely that this pathway explains the observed relationship between low cognitive functioning and testing positive for HIV/AIDS.

Lack of detection of an association between delayed recall and seropositivity may be due to error in the measurement of delayed recall in Umeed. Although every effort was made to carry out interviews in an environment conducive to cognitive testing, it is possible that noise and interruptions to interviews had an impact, particularly on measurement of delayed recall, the more complex of the two cognitive tests. Measurement error may have led to some random misclassification of delayed recall test results, which may have contributed to masking a true association between delayed recall test results and testing positive.

\section{Conclusion}

Umeed study findings provide tentative evidence that prior to knowledge of HIV status, low cognitive test scores (and perhaps CMD), may be associated with seropositivity among people coming for HIV-testing. Our findings suggest that a biological mechanism may contribute to the high prevalence of CMD and poor cognitive functioning commonly found among people living with HIV/AIDS. Impaired cognitive functioning and depression-like symptoms may be the result of the same underlying neurological damage caused by the presence of HIV in the brain. CMD and cognitive impairment may overlap to a greater extent than previously assumed. In order to clarify the relationship between CMD, cognitive impairment and HIV/AIDS, further research among pre-diagnosis samples is necessary. It would be helpful to include detailed assessments of key cognitive domains. If a closer interrelationship between cognitive functioning and CMD among people living with HIV/AIDS is demonstrated, this may have implications for the way in which we measure and treat CMD and cognitive functioning among people living with HIV/AIDS. It will be important to explore the possibility of early behavioural markers (such as apathy) as predictors of later cognitive decline. Depending on the outcome of future research, routine integration of screening for both CMD and cognitive deficits within Voluntary Counselling and Testing should be considered.

\section{Competing interests}

The authors declare that they have no competing interests.

\section{Authors' contributions}

MP \& RM conceived of the study and planned analyses. RM carried out analyses. VP \& MA participated in the design of the study. RM \& PK coordinated study staff and data collection. SR provided provided on-site supervision during data collection. RP advised on study design and ethical considerations. All authors read and approved the final manuscript.

\section{Acknowledgements}

The Umeed study was funded by grants from Psychiatry Research Trust and Parkes Foundation. We are grateful to National AIDS Control Organisation for approving the Umeed study. We are grateful to the Umeed research team:

Priti Girap, Supriya Harmalkar, Rakesh Kumar. Thanks also to Neerja Chowdhary, Maryam Shahmanesh, Smita Naik and the staff at the Goa Medical College Integrated Counselling and Testing Centre. And thanks to all those who took part in the study.

\section{Author details}

${ }^{1}$ Health Service \& Population Research Department, Institute of Psychiatry, Kings College London, London, UK. ${ }^{2}$ Department of Nutrition and Public Health Intervention Research, London School of Hygiene \& Tropical Medicine, London, UK. ${ }^{3}$ Sangath, Goa, India. ${ }^{4}$ National AIDS Research Institute, Pune, India. ${ }^{5} \mathrm{Goa}$ Medical College, Goa, India.

Received: 23 November 2012 Accepted: 4 March 2013 Published: 7 March 2013

\section{References}

1. Bing EG, Burnam MA, Longshore D, Fleishman JA, Sherbourne CD, London AS, Turner BJ, Eggan F, Beckman R, Vitiello B, et al: Psychiatric disorders and drug use among human immunodeficiency virus-infected adults in the United States. Arch Gen Psychiatry 2001, 58(8):721-728.

2. Ciesla JA, Roberts JE: Meta-analysis of the relationship between HIV infection and risk for depressive disorders. Am J Psychiatry 2001, 158(5):725-730.

3. Gupta R, Dandu M, Packel L, Rutherford G, Leiter K, Phaladze N, Korte FP lacopino V, Weiser SD: Depression and HIV in Botswana: a populationbased study on gender-specific socioeconomic and behavioral correlates. PLoS One 2010, 5(12):e14252.

4. Nakasujja N, Skolasky RL, Musisi S, Allebeck P, Robertson K, Ronald A, Katabira E, Clifford DB, Sacktor N: Depression symptoms and cognitive function among individuals with advanced HIV infection initiating HAART in Uganda. BMC Psychiatry 2010, 10:44.

5. Nakimuli-Mpungu E, Musisi S, Katabira E, Nachega J, Bass J: Prevalence and factors associated with depressive disorders in an HIV + rural patient population in southern Uganda. J Affect Disord 2011, 135(1-3):160-167.

6. Sahay S, Phadke M, Brahme R, Paralikar V, Joshi V, Sane S, Risbud A, Mate S, Mehendale S: Correlates of anxiety and depression among HIV testseekers at a voluntary counseling and testing facility in Pune, India. Qual Life Res 2007, 16(1):41-52.

7. Amberbir A, Woldemichael K, Getachew S, Girma B, Deribe K: Predictors of adherence to antiretroviral therapy among HIV-infected persons: a prospective study in Southwest Ethiopia. BMC Public Health 2008, 8:265.

8. Peltzer K, Friend-du Preez N, Ramlagan S, Anderson J: Antiretroviral treatment adherence among HIV patients in KwaZulu-Natal, South Africa. BMC Public Health 2010, 10:111.

9. Byakika-Tusiime J, Crane J, Oyugi JH, Ragland K, Kawuma A, Musoke P, Bangsberg DR: Longitudinal antiretroviral adherence in HIV + Ugandan parents and their children initiating HAART in the MTCT-Plus family treatment model: role of depression in declining adherence over time. AIDS Behav 2009, 13(Suppl 1):82-91.

10. Antelman G, Kaaya S, Wei R, Mbwambo J, Msamanga Gl, Fawzi WW, Fawzi MC: Depressive symptoms increase risk of HIV disease progression and mortality among women in Tanzania. J Acquir Immune Defic Syndr 2007, 44(4):470-477.

11. Leserman J: HIV disease progression: depression, stress, and possible mechanisms. Biol Psychiatry 2003, 54(3):295-306.

12. Robertson K, Liner J, Heaton R: Neuropsychological assessment of HIVinfected populations in international settings. Neuropsychol Rev 2009, 19(2):232-249.

13. Heaton RK, Grant I, Butters N, White DA, Kirson D, Atkinson JH, McCutchan JA, Taylor MJ, Kelly MD, Ellis RJ, et al: The HNRC 500-neuropsychology of HIV infection at different disease stages. HIV Neurobehavioral Research Center. J Int Neuropsychol Soc 1995, 1(3):231-251.

14. Wilkie FL, Goodkin K, Eisdorfer C, Feaster D, Morgan R, Fletcher MA, Blaney $\mathrm{N}$, Baum M, Szapocznik J: Mild cognitive impairment and risk of mortality in HIV-1 infection. J Neuropsychiatry Clin Neurosci 1998, 10(2):125-132.

15. Hinkin CH, Hardy DJ, Mason KI, Castellon SA, Durvasula RS, Lam MN, Stefaniak M: Medication adherence in HIV-infected adults: effect 
of patient age, cognitive status, and substance abuse. AIDS 2004, 18(Suppl 1):S19-25.

16. van Gorp WG, Baerwald JP, Ferrando SJ, McElhiney MC, Rabkin JG: The relationship between employment and neuropsychological impairment in HIV infection. J Int Neuropsychol Soc 1999, 5(6):534-539.

17. Bonnet F, Amieva H, Marquant F, Bernard C, Bruyand M, Dauchy FA, Mercie P, Greib C, Richert L, Neau D, et al: Cognitive disorders in HIV-infected patients: are they HIV-related? AIDS 2013, 27(3):391-400.

18. Simbayi LC, Kalichman SC, Strebel A, Cloete A, Henda N, Mqeketo A: Disclosure of HIV status to sex partners and sexual risk behaviours among HIV-positive men and women, Cape Town, South Africa. Sex Transm Infect 2007, 83(1):29-34

19. Steward WT, Chandy S, Singh G, Panicker ST, Osmand TA, Heylen E, Ekstrand $\mathrm{ML}$ : Depression is not an inevitable outcome of disclosure avoidance: HIV stigma and mental health in a cohort of HIV-infected individuals from Southern India. Psychol Health Med 2011, 16(1):74-85.

20. Lawson MA, Kelley KW, Dantzer R: Intracerebroventricular administration of HIV-1 Tat induces brain cytokine and indoleamine 2,3-dioxygenase expression: a possible mechanism for AIDS comorbid depression. Brain Behav Immun 2011, 25(8):1569-1575.

21. Maj M, Satz P, Janssen R, Zaudig M, Starace F, D'Elia L, Sughondhabirom B, Mussa M, Naber D, Ndetei D, et al: WHO neuropsychiatric AIDS study, cross-sectional phase II. Neuropsychological and neurological findings. Arch Gen Psychiatry 1994, 51(1):51-61.

22. Rochat TJ, Richter LM, Doll HA, Buthelezi NP, Tomkins A, Stein A Depression among pregnant rural South African women undergoing HIV testing. JAMA 2006, 295(12):1376-1378.

23. Lawler K, Mosepele M, Ratcliffe S, Seloilwe E, Steele K, Nthobatsang R, Steenhoff A: Neurocognitive impairment among HIV-positive individuals in Botswana: a pilot study. J Int AIDS Soc 2010, 13:15.

24. Spitzer RL, Kroenke K, Williams JB: Validation and utility of a self-report version of PRIME-MD: the PHQ primary care study. Primary Care evaluation of mental disorders. Patient health questionnaire. JAMA 1999 282(18):1737-1744

25. Patel V, Araya R, Chowdhary N, King M, Kirkwood B, Nayak S, Simon G, Weiss HA: Detecting common mental disorders in primary care in India: a comparison of five screening questionnaires. Psychol Med 2008, 38(2):221-228

26. Spitzer RL, Kroenke K, Williams JB, Lowe B: A brief measure for assessing generalized anxiety disorder: the GAD-7. Arch Intern Med 2006, 166(10):1092-1097

27. Ustun TB, Goldberg D, Cooper J, Simon GE, Sartorius N: New classification for mental disorders with management guidelines for use in primary care: ICD-10 PHC chapter five. Br J Gen Pract 1995, 45(393):211-215.

28. Kessler RC, Ormel J, Demler O, Stang PE: Comorbid mental disorders account for the role impairment of commonly occurring chronic physical disorders: results from the National Comorbidity Survey. J Occup Environ Med 2003, 45(12):1257-1266.

29. Das-Munshi J, Goldberg D, Bebbington PE, Bhugra DK, Brugha TS, Dewey $M E$, Jenkins $R$, Stewart $R$, Prince M: Public health significance of mixed anxiety and depression: beyond current classification. Br J Psychiatry 2008, 192(3):171-177.

30. Carey KB, Carey MP, Chandra PS: Psychometric evaluation of the alcohol use disorders identification test and short drug abuse screening test with psychiatric patients in India. J Clin Psychiatry 2003, 64(7):767-774.

31. Pal HR, Jena R, Yadav D: Validation of the alcohol use disorders identification test (AUDIT) in urban community outreach and deaddiction center samples in north India. J Stud Alcohol 2004, 65(6):794-800.

32. D'Costa G, Nazareth I, Naik D, Vaidya R, Levy G, Patel V, King M: Harmful alcohol use in Goa, India, and its associations with violence: a study in primary care. Alcohol Alcohol 2007, 42(2):131-137.

33. Gaunekar $G$, Patel $V$, Rane A: The impact and patterns of hazardous drinking amongst male industrial workers in Goa, India. Soc Psychiatry Psychiatr Epidemiol 2005, 40(4):267-275.

34. Nayak MB, Bond JC, Cherpitel C, Patel V, Greenfield TK: Detecting alcoholrelated problems in developing countries: a comparison of 2 screening measures in India. Alcohol Clin Exp Res 2009, 33(12):2057-2066.

35. White DA, Taylor MJ, Butters N, Mack C, Salmon DP, Peavy G, Ryan L, Heaton RK, Atkinson JH, Chandler JL, et al: Memory for verbal information in individuals with HIV-associated dementia complex. HNRC Group. J Clin Exp Neuropsychol 1997, 19(3):357-366.

36. Ganguli M, Seaberg EC, Ratcliff GG, Belle SH, DeKosky ST: Cognitive stability over 2 years in a rural elderly population: the MoVIES project. Neuroepidemiology 1996, 15(1):42-50.

37. Prince M, Acosta D, Chiu H, Scazufca M, Varghese M: Dementia diagnosis in developing countries: a cross-cultural validation study. Lancet 2003, 361(9361):909-917.

38. Kinyanda E, Hoskins S, Nakku J, Nawaz S, Patel V: Prevalence and risk factors of major depressive disorder in HIV/AIDS as seen in semi-urban Entebbe district, Uganda. BMC Psychiatry 2011, 11:205.

39. Marwick KF, Kaaya SF: Prevalence of depression and anxiety disorders in HIV-positive outpatients in rural Tanzania. AIDS Care 2010, 22(4):415-419.

40. Cohen MH, Fabri M, Cai X, Shi Q, Hoover DR, Binagwaho A, Culhane MA, Mukanyonga $\mathrm{H}$, Karegeya DK, Anastos K: Prevalence and predictors of posttraumatic stress disorder and depression in HIV-infected and at-risk Rwandan women. J Womens Health (Larchmt) 2009, 18(11):1783-1791.

41. Patel V, Kirkwood BR, Pednekar S, Weiss H, Mabey D: Risk factors for common mental disorders in women. Population-based longitudinal study. Br J Psychiatry 2006, 189:547-555.

42. Patel V, Pereira J, Coutinho L, Fernandes R, Fernandes J, Mann A: Poverty, psychological disorder and disability in primary care attenders in Goa, India. Br J Psychiatry 1998, 172:533-536.

43. Skinner D, Mfecane S: Stigma, discrimination and the implications for people living with HIV/AIDS in South Africa. SAHARA J 2004, 1(3):157-164

44. Rahangdale L, Banandur P, Sreenivas A, Turan JM, Washington R, Cohen CR: Stigma as experienced by women accessing prevention of parent-tochild transmission of HIV services in Karnataka, India. AIDS Care 2010, 22(7):836-842.

45. Piot $P$, Greener $R$, Russell $S$ : Squaring the circle: AIDS, poverty, and human development. PLoS Med 2007, 4(10):1571-1575.

46. Dantzer R, O'Connor JC, Freund GG, Johnson RW, Kelley KW: From inflammation to sickness and depression: when the immune system subjugates the brain. Nat Rev Neurosci 2008, 9(1):46-56.

47. Safren SA, Thomas BE, Mimiaga MJ, Chandrasekaran V, Menon S, Swaminathan S, Mayer KH: Depressive symptoms and human immunodeficiency virus risk behavior among men who have sex with men in Chennai, India. Psychol Health Med 2009, 14(6):705-715.

48. Hoare J, Fouche JP, Spottiswoode B, Joska JA, Schoeman R, Stein DJ, Carey PD: White matter correlates of apathy in HIV-positive subjects: a diffusion tensor imaging study. J Neuropsychiatry Clin Neurosci 2010, 22(3):313-320.

49. Sikkema KJ, Watt MH, Meade CS, Ranby KW, Kalichman SC, Skinner D, Pieterse D: Mental health and HIV sexual risk behavior among patrons of alcohol serving venues in Cape Town, South Africa. J Acquir Immune Defic Syndr 2011, 57(3):230-237.

50. ludicello JE, Woods SP, Parsons TD, Moran LM, Carey CL, Grant I: Verbal fluency in HIV infection: a meta-analytic review. J Int Neuropsychol Soc 2007, 13(1):183-189.

51. Gupta JD, Satishchandra P, Gopukumar K, Wilkie F, Waldrop-Valverde D, Ellis R, Ownby R, Subbakrishna DK, Desai A, Kamat A, et al: Neuropsychological deficits in human immunodeficiency virus type 1 clade C-seropositive adults from South India. J Neurovirol 2007, 13(3):195-202.

52. Yepthomi T, Paul R, Vallabhaneni S, Kumarasamy N, Tate DF, Solomon S, Flanigan T: Neurocognitive consequences of HIV in southern India: a preliminary study of clade C virus. J Int Neuropsychol Soc 2006, 12(3):424-430.

53. Uekermann J, Daum I, Schlebusch P, Wiebel B, Trenckmann U: Depression and cognitive functioning in alcoholism. Addiction 2003, 98(11):1521-1529.

54. Fromme K, D'Amico EJ, Katz EC: Intoxicated sexual risk taking: an expectancy or cognitive impairment explanation? J Stud Alcohol 1999, 60(1):54-63

\section{doi:10.1186/1471-2458-13-204}

Cite this article as: Mayston et al: Symptoms of common mental disorder and cognitive associations with seropositivity among a cohort of people coming for testing for HIV/AIDS in Goa, India: a crosssectional survey. BMC Public Health 2013 13:204. 